\title{
CONTRAST-AGENT-ENHANCED ULTRASOUND THERMAL ABLATION
}

\author{
Yao-Sheng Tung, * HaO-Li Liu, ${ }^{\dagger}$ Chih-Ching Wu, ${ }^{\ddagger}$ Kuen-Cheng Ju,* \\ Wen-Shiang Chen, ${ }^{\ddagger}$ and WIN-Li Lin* \\ *Institute of Biomedical Engineering, National Taiwan University, Taipei; $†$ Department of Electrical Engineering, \\ Chang-Gung University, Tao Yuan; ${ }^{*}$ Department of Mechanical Engineering, National Taiwan University, Taipei; \\ and ${ }^{\S}$ Department of Physical Medicine and Rehabilitation, National Taiwan University Hospital, Taipei, Taiwan
}

(Received 12 October 2005, revised 21 March 2006, in final form 6 April 2006)

\begin{abstract}
The small thermal lesions induced when using high-intensity focused ultrasound (HIFU) to ablate tumors results in long treatment duration. In this study, the effect of using ultrasound contrast agent (UCA, Definity ${ }^{\circledR}$ ) to enhance the ultrasound (US) thermal effects and, thus to enlarge the lesion size, was studied in transparent tissue phantoms insonified by $1.85-\mathrm{MHz}$ US with acoustical powers of 28.9 and $40.4 \mathrm{~W}$. The experimental results show that the lesion size depended strongly on the electrical power and the concentration of UCA. UCA also reduced the power required to form a lesion of a certain size by about $30 \%$. However, UCA moved the greatest heating position from the transducer focus, by $2.16 \mathrm{~cm}$ for $0.015 \% \mathrm{UCA}$ at $40.4 \mathrm{~W}$, and with lesions forming at the surface for UCA concentrations higher than $0.1 \%$. An optimal result was obtained when using $0.001 \%$ UCA and 28.9-W US, which produced a lesion 12 times larger and an acceptable shift (less than half of the lesion length). UCA can effectively increase the size of the HIFU lesions, but lesion shift should be carefully considered while performing HIFU ablations. (E-mail: wenshiang@ ha.mc.ntu.edt.tw) @ 2006 World Federation for Ultrasound in Medicine \& Biology.
\end{abstract}

Key Words: Ultrasound, High-intensity focused ultrasound, Cancer, Inertial cavitation, Thermal ablation, Ultrasound contrast agent.

\section{INTRODUCTION}

High-intensity focused ultrasound (HIFU) is a new modality of cancer therapy using the thermal effects of US to ablate tumors. The ultrasound (US) energy can be given extracorporeally and focused in a small region inside the body $(<1 \mathrm{~cm}$ in length) for a transducer of megahertz frequencies. The local temperature increases immediately to a level (usually more than $65^{\circ} \mathrm{C}$ ), at which cell death occurs. The fast temperature drop below $43^{\circ} \mathrm{C}$ outside the focal region results in little or no thermal damage in the intervening tissue (between the transducer surface and focus). Surgical incision is not necessary for treating a deep tumor with HIFU and, thus, HIFU is generally considered as a noninvasive treatment modality. Moreover, HIFU does not involve radioactivity and so can be administered repeatedly.

However, some remaining problems need to be addressed before HIFU can be used extensively in clin-

Address correspondence to: Wen-Shiang Chen, MD, PhD, Department of Physical Medicine and Rehabilitation, National Taiwan University Hospital, No. 7, Zhongshan S. Rd., Taipei 100, Taiwan.

E-mail: wenshiang@ha.mc.ntu.edu.tw ical practice. One of the major disadvantages of HIFU ablation is the small lesion size and the resulting long treatment duration. As past and present clinical trials show, a complete ablation usually takes several hours. Anesthesia is usually necessary, which increases the risks to patients. Therefore, an efficient method for enlarging the formed lesion and thereby reducing the ablation duration needs to be developed. In general, increasing the US intensity or the ablation duration will enlarge the lesion, but these methods may also overheat the surrounding normal tissue. Previous research shows that the presence of bubbles near the HIFU focus can result in a larger lesion (Fujishiro et al. 1998; Yu et al. 2004; Kaneko et al. 2005). The administration of contrast microbubbles can effectively reduce the treatment time or the required US intensity (Tran et al. 2003). Different types of UCA have been shown to exhibit different efficiencies in the heating and coagulation of liver tissue (Takegami et al. 2005).

The objective of this study was to elucidate the effects of an ultrasound contrast agent (UCA) on the formation of thermal lesions inside transparent tissue 


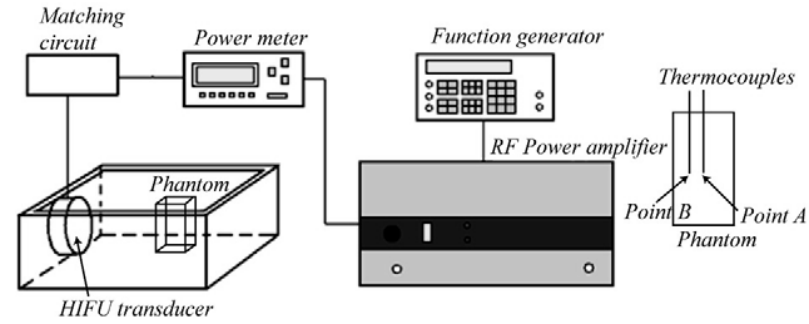

Fig. 1. Experimental set-up. Thermocouples A and B were inserted into the points $\mathrm{A}$ and $\mathrm{B}$, respectively, in the tissuemimicking phantom as indicated.

phantoms. It was hypothesized that (1) the thermal lesion can be enlarged by introducing UCA, (2) the lesion size depends on the concentration of UCA and (3) the presence of UCA also induces migration of the maximal heating center from the transducer focus. We were also interested in understanding the mechanisms of lesion formation in the absence and presence of UCA microbubbles.

\section{MATERIALS AND METHODS}

\section{Ultrasound system}

Figure 1 shows a schematic of the experimental set-up. A single-element focused piezoelectric transducer (Imasonic, Besançon, France) was used as the source of HIFU radiation. The diameter, curvature, center frequency and efficiency of the HIFU transducer were 10 $\mathrm{cm}, 12.5 \mathrm{~cm}, 1.85 \mathrm{MHz}$ and 65 to $75 \%$ (depending on the driving powers), respectively. The efficiency was determined by dividing the acoustic powers obtained using force balance method by electrical powers in degassed water at $20^{\circ} \mathrm{C} \pm 3^{\circ} \mathrm{C}$. Using extrapolation, the focal pressure in water was estimated to be 8.71 and 10.28 $\mathrm{MPa}$ (peak-negative pressures) for electrical powers of 50 and $70 \mathrm{~W}$ (acoustic powers of 28.9 and $40.4 \mathrm{~W}$ ), respectively. The length of the $-3 \mathrm{~dB}$ intensity in the axial direction was $9.16 \mathrm{~mm}$ and the radii of the $-6-\mathrm{dB}$ intensity in the directions perpendicular to the beam axis was $0.51 \mathrm{~mm}$. Experiments were performed in a $24 \times 21$ $\times 15-\mathrm{cm}$ acrylic tank containing degassed water at $37^{\circ} \mathrm{C}$. The radiofrequency (RF) signal was supplied by a function generator (33120A, Agilent, Palo Alto, CA, USA) whose output was amplified by an RF power amplifier (150A250, Amplifier Research, Souderton, PA, USA). The incident and reflected powers were measured using a power meter (4421, Bird, Cleveland, OH, USA).

\section{Tissue-mimicking phantom}

The transparent tissue phantoms used in the current study were constructed from an acrylamide/bis gel according to Takegami et al. (2004). The components of the phantom are listed in Table 1. Definity ${ }^{\circledR}$ (DuPont, North Billerica, MA, USA) was used as the UCA. To distribute the UCA evenly throughout the phantom, it was added to the phantom and shaken gently before the phantom cured, in order to make the bubbles uniformly distributed. To make a phantom with $0.1 \%$ UCA (v/v; equivalent to $1.2 \times 10^{4}$ bubbles $/ \mathrm{mm}^{3}$ ), $0.1 \mathrm{~mL}$ of UCA was drawn from the vial and added directly to the 100-mL mixture listed in Table 1. The attenuation coefficient of phantoms without UCA was $2.48 \mathrm{NP} / \mathrm{m} / \mathrm{MHz}$. Because the interrogating ultrasonic pulses interacted with the UCA bubbles in phantoms (e.g., inducing irreversible bubble destruction), the measured attenuation coefficients were inaccurate and are not given here.

\section{Experimental series}

All experiments were performed in an acrylic tank filled with tap water. The distance between the focal point and the phantom surface was $2.5 \mathrm{~cm}$. The total heating time was $30 \mathrm{~s}$ in every experiment.

Experiment 1: Energy dependence without UCA. The sizes and shapes of the thermal lesions formed at electrical powers of 50,60, 70, 80, 90 and $100 \mathrm{~W}$ were recorded as a function of time. The total exposure time was $30 \mathrm{~s}$ for each test, which is slightly longer than those used in previous studies (16 to $20 \mathrm{~s}$ ) (McDannold et al. 2003; Tempany et al. 2003). A 30-s exposure was selected because of the low attenuation coefficient of the phantoms in use. Five samples were used for each electrical power.

Experiment 2: UCA concentration. UCA at concentrations of $0 \%$ (control), $0.001 \%, 0.005 \%, 0.01 \%$, $0.015 \%, 0.025 \%, 0.05 \%, 0.075 \%$ and $0.1 \%$ (v/v) was mixed uniformly inside the polyacrylamide gel phantoms. The relationship between the UCA concentrations and lesion shapes, volumes and volume enlargement ratio (VER) were compared at electrical powers of 50 and $70 \mathrm{~W}$. Nine to 12 samples were used for each concentration of UCA-added phantoms. The reduction in the power required to produce the same size of lesion

Table 1. Composition of the acrylamide phantoms

\begin{tabular}{lc}
\hline \multicolumn{1}{c}{ Component } & $\begin{array}{c}\text { Volume } \\
(\mathrm{mL})\end{array}$ \\
\hline Egg white & 30 \\
Degassed water & 40 \\
Acrylamide/bis, 19:1, 40\% solution & 24.8 \\
10\% (v/v) ammonium persulfate & 0.5 \\
N,N,N',N'-tetramethylethylenediamine & 0.2 \\
Glycerol, anhydrous & 4.5 \\
\hline Total & 100 \\
\hline
\end{tabular}



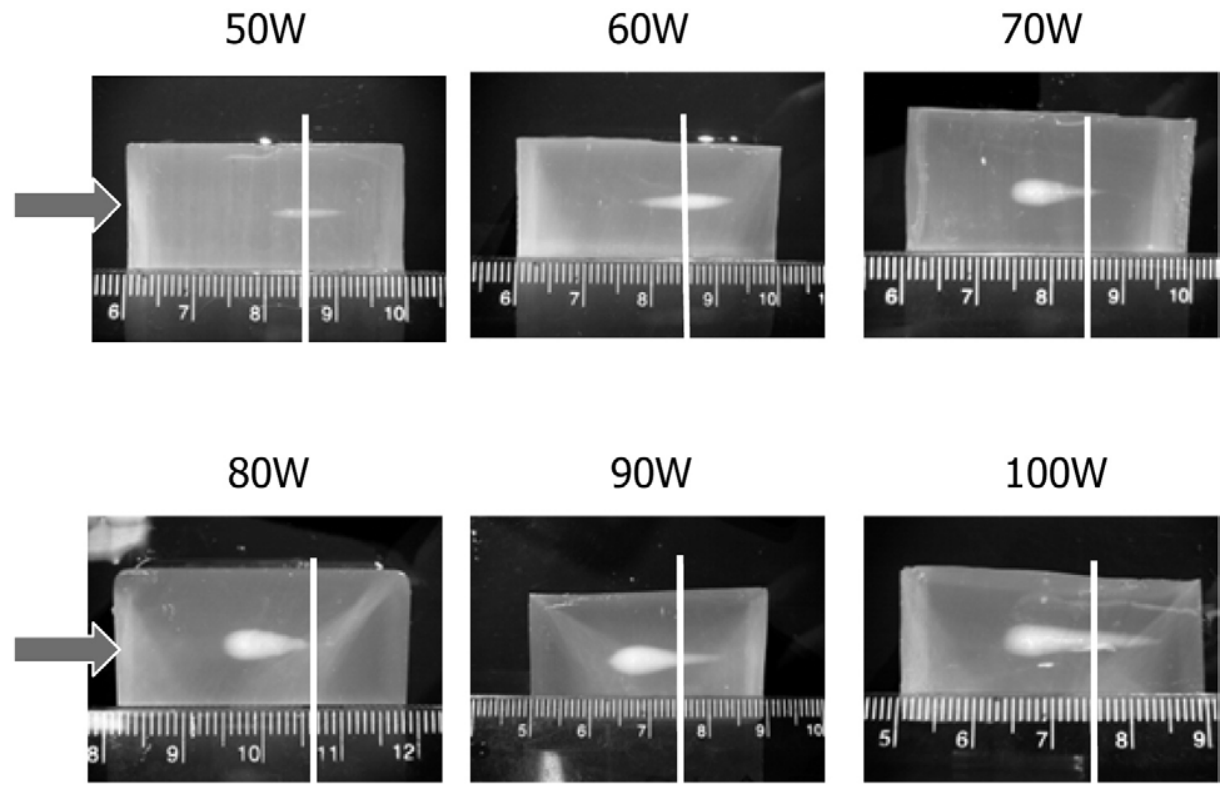

Fig. 2. Lesions formed at different electrical powers after heating for $30 \mathrm{~s}$. The vertical solid lines represent the focal plane. The arrow indicates the incident sonication direction.

after the addition of UCA was also estimated. Moreover, because bubbles could make the lesion extend toward the transducer, the distances between the focus and lesion were measured.

Experiment 3: Mechanisms of lesion formation. To understand the mechanisms of lesion formation and transformation, the lesion growth with and without UCA at $70 \mathrm{~W}$ was monitored in real-time continuously by a charge coupled device camera $(352 \times 240$ pixels $)$. The internal temperature change was also monitored using two T-type thermocouples inserted at $2.5 \mathrm{~cm}$ (transducer focus, point A) and $1.25 \mathrm{~cm}$ (half-way between the focus and the phantom surface, point B) from the surface of the phantom (Fig. 1). The concentration of UCA used in this experiment was $0.005 \%$.

\section{Definitions and calculations}

For lesion migration, the shift was defined as the distance between the geometric focus and the position along the beam axis where maximal lesion width was obtained. When the shift distance was less than half of the lesion length, it was considered to be acceptable. VER was defined as the ratio of the volumes of the lesions formed in phantoms with and without UCA at the same power level. Also, the direction toward the transducer surface was defined as "backward" direction.

To estimate the volume of a thermal lesion, the recorded images were first traced by a custom-made Matlab (The Math Works, Natick, MA, USA) program for lesion borders, which were then fine interpolated by using cubic spline polynomials. Because lesions were assumed to be axially symmetrical, their volumes $(V)$ could be approximated by $n$ slices perpendicular to their central axes, according to the following equation:

$$
V=\sum_{1}^{n} \pi \cdot\left(r_{n}\right)^{2} \cdot D
$$

where $r$ is the distance from a point at the lesion border to its central axis and D is the thickness of each slice.

\section{RESULTS}

Experiment 1: Energy dependence. The results of experiment 1 are shown in Fig. 2. The lesion was cigarshaped when the power was 50 and $60 \mathrm{~W}$ and was tadpole-shaped at $\geq 70 \mathrm{~W}$. The VER values relative to the lesions formed at the power of $50 \mathrm{~W}$ are listed in

Table 2. VER values of lesions formed by HIFU driven at different electrical powers in the absence of UCA relative to control lesions formed at $50 \mathrm{~W}$

\begin{tabular}{lcccccc}
\hline Power $(\mathrm{W})$ & 50 & 60 & 70 & 80 & 90 & 100 \\
Volume $\left(\mathrm{mm}^{3}\right)$ & $19.2 \pm 2.7$ & $44.2 \pm 3.4$ & $74.0 \pm 5.1$ & $93.9 \pm 10.4$ & $152.1 \pm 9.0$ & $191.6 \pm 21.1$ \\
\hline
\end{tabular}



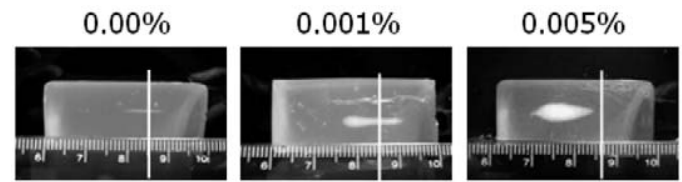

$0.01 \%$

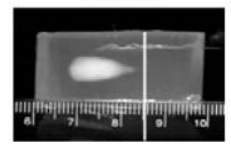

$0.015 \%$

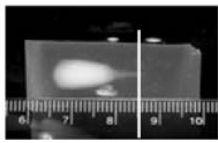

$0.025 \%$

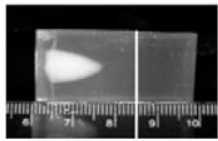

$0.05 \%$
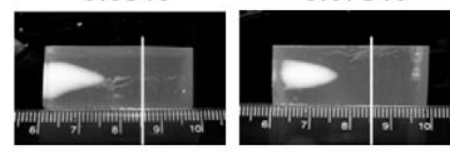

(a)
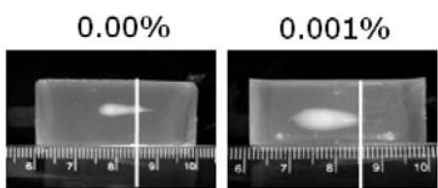

$0.005 \%$

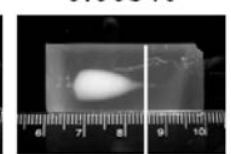

$0.01 \%$

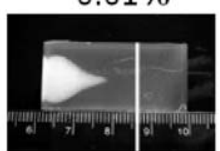

$0.015 \%$

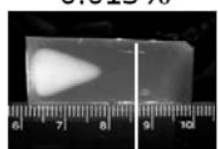

$0.025 \%$

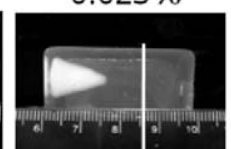

$0.05 \%$
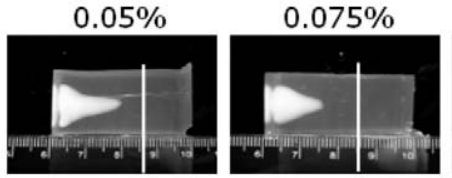

$0.10 \%$

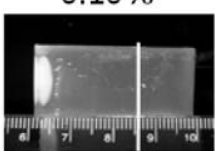

(b)

Fig. 3. Lesions formed after introducing UCA of different concentrations at (a) $50 \mathrm{~W}$ and (b) $70 \mathrm{~W}$. The total heating time was $30 \mathrm{~s}$ and the transducer was on the left side.

Table 2. The mean lesion volume increased linearly with the US power.

Experiment 2: UCA concentration. The relationship between the UCA concentration and lesion shape at 50 and $70 \mathrm{~W}$ is shown in Fig. 3. The size and backward shift of lesions both increased with the UCA concentration, with the lesion forming near the surface of the phantom for concentrations greater than $0.1 \%$. The VER values for different concentrations of UCA compared with controls at 50 and $70 \mathrm{~W}$ are listed in Table 3 , which indicates that the inclusion of UCA increased the lesion size by up to 65 times.

UCA also reduced the power required to form a lesion of a certain size. The effect of using UCA to reduce the electrical power driving the HIFU transducer is indicated in Tables 2 and 3. For example, $0.001 \%$ UCA at $50 \mathrm{~W}$ produced a lesion with a size close to that produced without UCA at $70 \mathrm{~W}$. By extrapolation, similarly-sized lesions were formed with $0.001 \% \mathrm{UCA}$ at 70 $\mathrm{W}$, and no UCA at $100 \mathrm{~W}$. This indicates that the use of UCA achieved a $30 \%$ reduction in the required electrical power.

The relationship between the concentration of UCA and the backward shift of lesions at 50 and $70 \mathrm{~W}$ is given in Table 4. The shift increased with the UCA concentration. Moreover, at the same concentration of UCA, the backward shift of the lesion was larger at $70 \mathrm{~W}$ than at $50 \mathrm{~W}$.

Experiment 3: Mechanisms of lesion formation. The lesion growth in the control and $0.005 \%$ UCA groups at $70 \mathrm{~W}$ are shown in Fig. 4a and b, respectively. No protein denaturing was evident until after $3 \mathrm{~s}$ of sonication in the control group (Fig. 4a). After $6 \mathrm{~s}$, a sudden flash similar to an explosion occurred at the focus. The lesion subsequently grew rapidly toward the transducer, but this slowed gradually by $12 \mathrm{~s}$ when the lesion began to grow laterally. A tadpole-shaped lesion was formed at the end of $30 \mathrm{~s}$ of sonication. Figure $4 \mathrm{~b}$ shows the ablation process for a phantom containing $0.005 \%$ UCA. Unlike controls, HIFU ablation in phantoms containing UCA resulted in multiple white dots within $1 \mathrm{~s}$ of sonication along the central axis of US propagation. The lesion grew over time and appeared to originate from these small white dots. The final lesion volume was

Table 3. VER values for different concentrations of UCA relative to control lesions formed at (a) $50 \mathrm{~W}$ and (b) 70 $\mathrm{W}$ in the absence of UCA $(\mathrm{n}=7)$

\begin{tabular}{lccccc}
\hline \multicolumn{5}{c}{ (a) $50 \mathrm{~W}$} \\
\hline $\begin{array}{l}\text { Concentration } \\
\text { VER mean }\end{array}$ & $0.000 \%$ & $0.001 \%$ & $0.005 \%$ & $0.010 \%$ & $0.015 \%$ \\
& $1.00 \pm 0.14$ & $3.55 \pm 0.59$ & $11.67 \pm 2.16$ & $22.34 \pm 1.73$ & $27.02 \pm 4.42$ \\
\hline Concentration & $0.000 \%$ & (b) $70 \mathrm{~W}$ & & & \\
VER* mean & $1.00 \pm 0.07$ & $0.001 \%$ & $0.005 \%$ & $0.010 \%$ & $0.015 \%$ \\
\hline
\end{tabular}

\footnotetext{
* VER $=$ lesion volume with UCA/lesion volume without UCA at the same power level.
} 
Table 4. Backward shift of a lesion after adding different concentrations of UCA at (a) $50 \mathrm{~W}$ and (b) $70 \mathrm{~W}(\mathrm{n}=7)$

(a) $50 \mathrm{~W}$

\begin{tabular}{lccccc} 
& & & & \\
Concentration & $0.000 \%$ & $0.001 \%$ & $0.005 \%$ & $0.010 \%$ & $0.015 \%$ \\
Mean shift $(\mathrm{cm})$ & $0.05 \pm 0.04$ & $0.67 \pm 0.11$ & $1.00 \pm 0.10$ & $1.54 \pm 0.10$ & $1.59 \pm 0.09$ \\
\hline \multicolumn{1}{c}{ (b) $70 \mathrm{~W}$} \\
\hline Concentration & $0.000 \%$ & $0.001 \%$ & $0.005 \%$ & $0.010 \%$ & $0.015 \%$ \\
Mean shift $(\mathrm{cm})$ & $0.67 \pm 0.04$ & $0.93 \pm 0.08$ & $1.48 \pm 0.12$ & $1.95 \pm 0.09$ & $2.03 \pm 0.10$ \\
\hline
\end{tabular}

larger for phantoms containing UCA than in the control phantoms. Moreover, no explosion occurred throughout the HIFU ablation in phantoms containing UCA.

The temperature changes during the lesion forma-

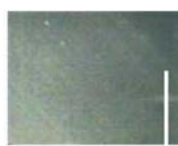

$3 s$

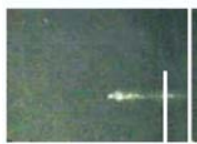

$8 \mathrm{~s}$

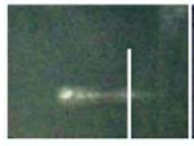

$15 \mathrm{~s}$

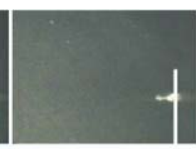

$6 \mathrm{~s}$

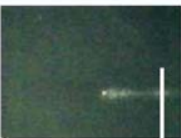

$9 \mathrm{~s}$

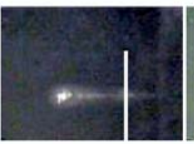

$10 \mathrm{~s}$

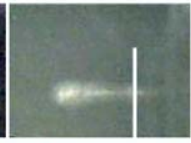

$25 \mathrm{~s}$

(a)
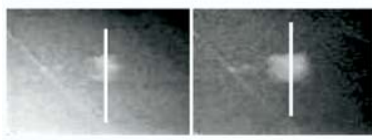

$1 \mathrm{~s}$

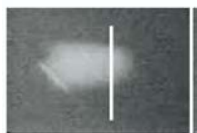

$2 \mathrm{~s}$

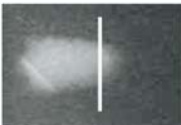

$12 \mathrm{~s}$

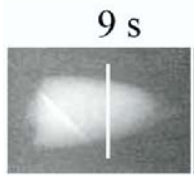

$23 \mathrm{~s}$

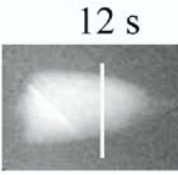

$25 \mathrm{~s}$

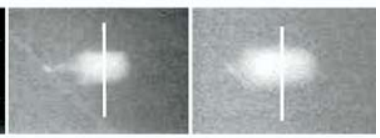

$4 \mathrm{~s}$

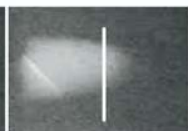

$16 \mathrm{~s}$

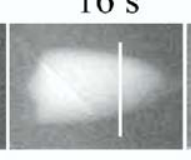

$28 \mathrm{~s}$

(b)

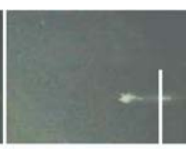

$7 \mathrm{~s}$

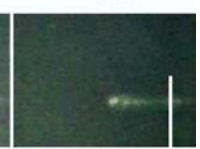

$12 \mathrm{~s}$

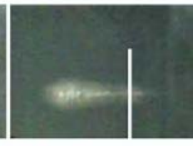

$30 \mathrm{~s}$

$6 \mathrm{~s}$

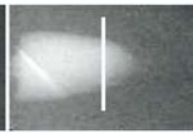

$20 \mathrm{~s}$

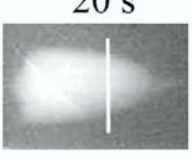

$30 \mathrm{~s}$
Fig. 4. Lesion growth of HIFU ablation at $70 \mathrm{~W}$ (a) Without and (b) With $0.005 \%$ UCA. The solid lines represent the focal plane and coincide with thermocouple A. Thermocouple B was placed $2.5 \mathrm{~cm}$ on the left side of the thermocouple A, but out of the shown pictures. The transducer was on the left side of both the thermocouple A and B. tion process of controls (at 50 and $70 \mathrm{~W}$ ) are shown in Fig. 5. At the HIFU focus for $70 \mathrm{~W}$, the temperature rose rapidly to just over $100^{\circ} \mathrm{C}$ after $5 \mathrm{~s}$, but rapidly dropped to $90^{\circ} \mathrm{C}$ after the explosion. Thereafter, the temperature decayed exponentially. No sudden temperature change was seen for the thermocouple placed between the phantom surface and the focus in controls. For the thermocouple placed between the phantom surface and the geometric focus (point $\mathrm{B}$ ), the temperature increased

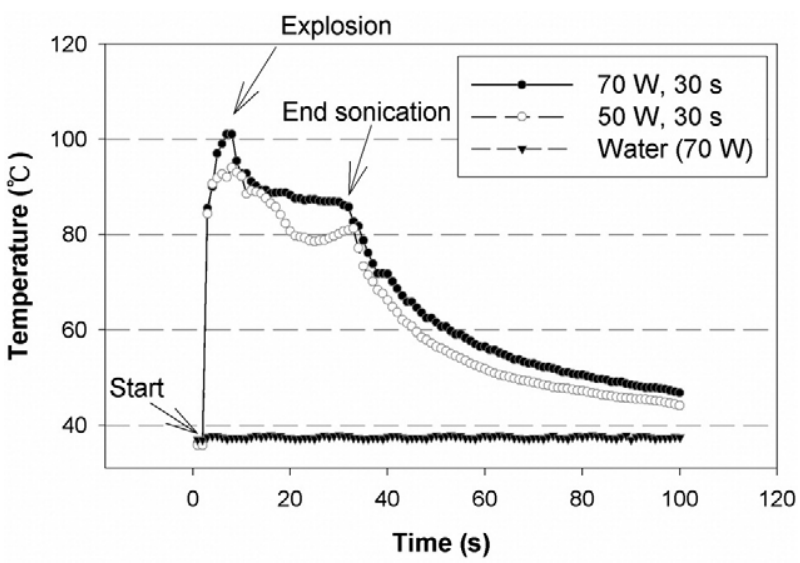

(a)

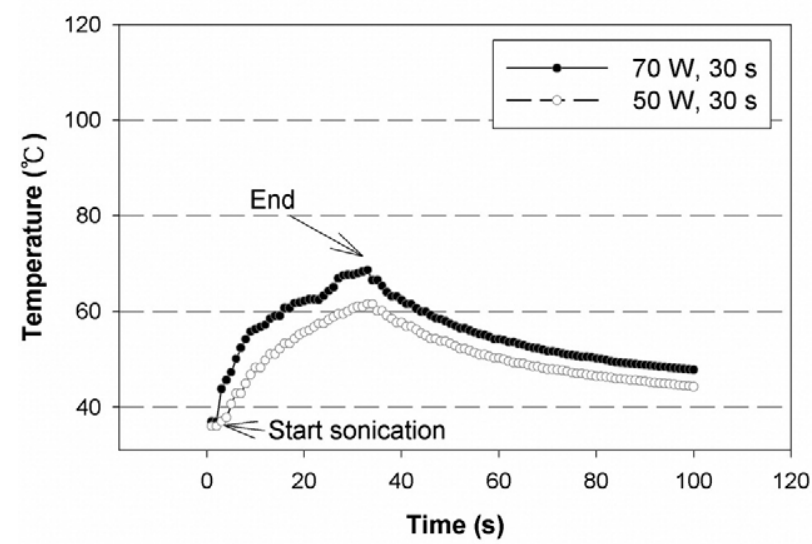

(b)

Fig. 5. Temperature in control phantoms for electrical powers of 50 and $70 \mathrm{~W}$ : (a) Point A, (b) Point B. 
Table 5. Maximal temperatures recorded by the implanted thermocouples at points $\mathrm{A}$ and $\mathrm{B}$ in phantoms with and without UCA at (a) $50 \mathrm{~W}$ and (b) $70 \mathrm{~W}(\mathrm{n}=5)$

(a)

\begin{tabular}{lcc}
\hline $50 \mathrm{~W}$ & Without UCA & With UCA \\
\hline Point A & $91.02 \pm 2.63^{\circ} \mathrm{C}$ & $63.16 \pm 3.19^{\circ} \mathrm{C}$ \\
Point B & $58.22 \pm 2.63^{\circ} \mathrm{C}$ & $67.26 \pm 1.75^{\circ} \mathrm{C}$ \\
\hline
\end{tabular}

(b)

\begin{tabular}{lcc}
\hline $70 \mathrm{~W}$ & Without UCA & With UCA \\
\hline Point A & $98.96 \pm 2.11^{\circ} \mathrm{C}$ & $68.26 \pm 3.04^{\circ} \mathrm{C}$ \\
Point B & $66.48 \pm 1.99^{\circ} \mathrm{C}$ & $83.20 \pm 1.65^{\circ} \mathrm{C}$ \\
\hline
\end{tabular}

over time during $30 \mathrm{~s}$ of ablation. After stopping sonication, the temperature at this thermocouple decayed exponentially. During the ablation, the peak temperatures at 50 and $70 \mathrm{~W}$ were $61.5^{\circ} \mathrm{C}$ and $68.2^{\circ} \mathrm{C}$, respectively. Note that the water temperature remained constant at $36^{\circ} \mathrm{C}$, irrespective of the electrical power. The maximal temperatures of the thermocouples at points $\mathrm{A}$ and $\mathrm{B}$ in phantoms with and without UCA are listed in Table 5.

The temperatures inside a phantom containing $0.005 \%$ UCA are shown in Fig. 6, which are very different from those in control phantoms (Fig. 5). There was no abrupt elevation in temperature at the focus (point A) after initiating the ablation process, irrespective of the electrical power. The temperature steadily increased over time, with the maximum temperatures at $50 \mathrm{~W}$ and $70 \mathrm{~W}$ being $63.7^{\circ} \mathrm{C}$ and $72.3^{\circ} \mathrm{C}$, respectively, which are clearly lower than those in the control groups at the same position. The maximum temperatures at $50 \mathrm{~W}$ and $70 \mathrm{~W}$ at point B (Fig. 6b) were $68.2^{\circ} \mathrm{C}$ and $85.4^{\circ} \mathrm{C}$, respectively, which were higher than those in the control groups at the same position and those at point $\mathrm{A}$.

The axial sections of the lesion with and without UCA at $70 \mathrm{~W}$ for $30 \mathrm{~s}$ of ablation are shown in Fig. 7. Holes were evident on the cut surface in control samples (Fig. 7a) but not in samples containing UCA (Fig. 7b).

\section{DISCUSSION}

The current study clearly demonstrates that UCA can substantially increase the size of HIFU lesions and reduce the energy required to form them. However, the lesions also moved backward from the expected focus when the concentration of UCA increased. The presence of UCA prevented abrupt temperature increases and the explosion phenomenon and also enlarged the high-temperature area and thereby resulted in more extensive protein denaturing.

The lesion size and its backward shift increased with the UCA concentration. A higher UCA concentra- tion means that there are more bubbles to scatter US energy and, thus, the phantom has a larger attenuation coefficient, which will result in more mechanical energy being converted to heat and, thus, the size of the lesion increases. However, a high attenuation also reduces the penetration of the US energy and, the lesion tends to form before the transducer focus. Once the concentration of the UCA exceeded a certain threshold (in our case, higher than $0.1 \%$ ), the lesion essentially formed at the surface of the phantom.

The control of lesion shift is critical for a successful HIFU treatment. Lesions were expected to form around the geometric focus. However, because of the presence of bubbles along the beam axis, lesion migration occurred and lesion shape changed. If the maximal heating center was within half of the lesion length, it still fell in the expected area of lesion formation. We considered this shift to be acceptable. On the contrary, if the maximal heating center resided outside the expected lesion area,

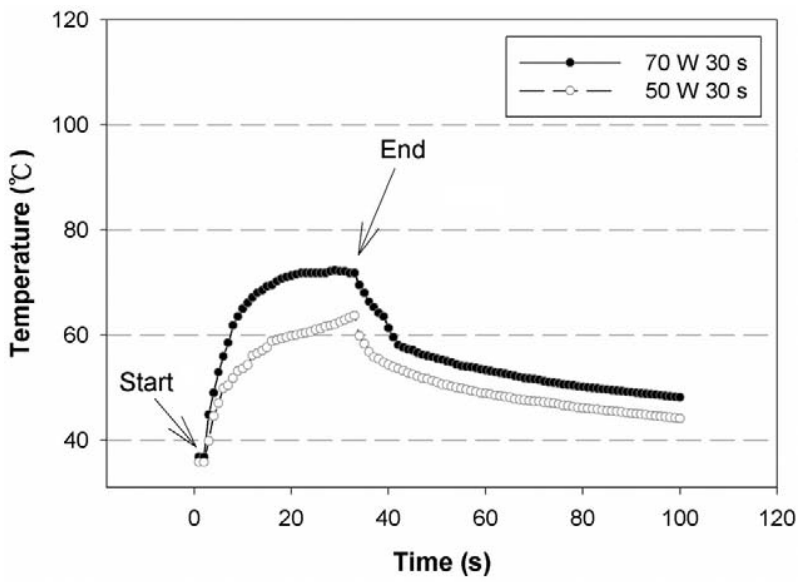

(a)

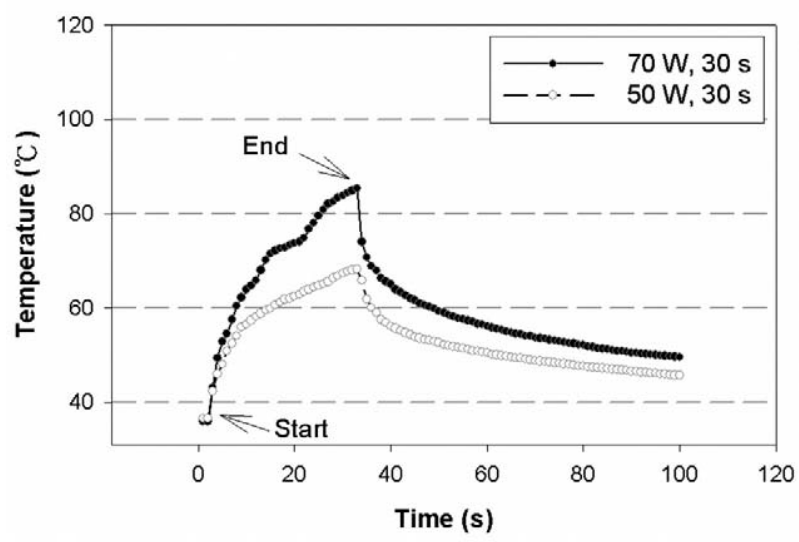

(b)

Fig. 6. Temperature in phantoms containing $0.005 \%$ UCA for electrical powers of 50 and $70 \mathrm{~W}$ : (a) point $\mathrm{A}$, (b) point $\mathrm{B}$. 

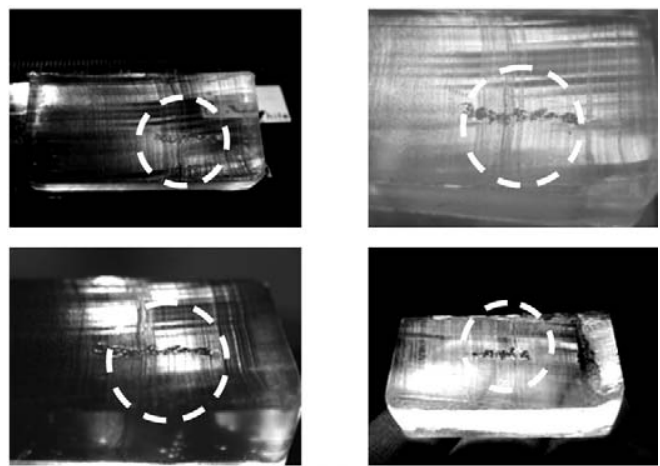

(a)

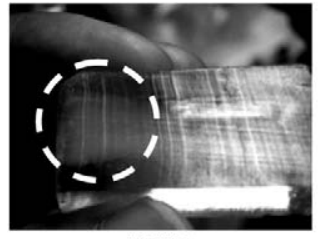

$0.015 \%$

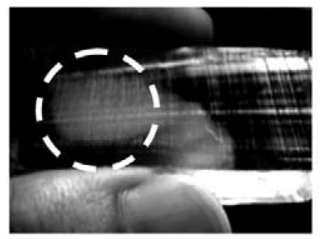

$0.005 \%$

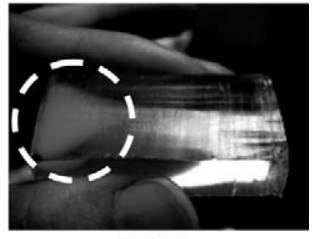

$0.010 \%$

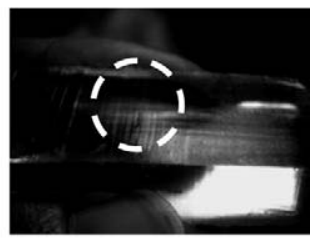

$0.001 \%$ (b)

Fig. 7. Axial sections of the lesion with and without UCA after insonifying at $70 \mathrm{~W}$ for $30 \mathrm{~s}$ (a) Without and (b) With UCA.

The regions-of-interest were circled by white dashed lines.

we speculated that a considerable off-target tissue might be destroyed. In the current study, only the lesion formed by $0.001 \%$ UCA at $50 \mathrm{~W}$ resulted in an acceptable shift.

Experiment 3 explored the possible mechanisms of lesion formation under various conditions by observing the real-time changes in lesion shape and phantom temperature. In the absence of UCA, cigar-shaped lesions were formed at $50 \mathrm{~W}$ by pure thermal effects, whereas the tadpole-shaped lesions at $70 \mathrm{~W}$ were related to overheating and boiling, as suggested by the delayed onset of the explosion events (Fig. 4a) coinciding with a temperature greater than $100^{\circ} \mathrm{C}$ (Fig. 5). A certain time (5 s, in this case) was required for enough heat accumulation before boiling occurred. Large vapor bubbles that formed at the central axis near the geometric focus reflected incident radiation and concentrated the energy backward from the focus, forcing the lesions to shift likewise. Thus, the focal temperature (point A) dropped to around $90^{\circ} \mathrm{C}$ after $6 \mathrm{~s}$. Further heat accumulation generated successive boiling and vapor bubbles that resulted in a greater backward shift. Our results are compatible with the results of Watkin (1996).

In contrast, no explosion events occurred during the entire process of thermal ablation in the presence of UCA microbubbles (Fig. 4b). The likely reason is that the US energy was scattered before reaching the temperature threshold to induce boiling. Because the incident US pressure was much higher than the inertial cavitation threshold for a micrometer-range bubble in water, inertial cavitation should occur (Carstensen et al. 1993; Deng et al. 1996). We have previously reported the existence of broadband noise (which is the signature of inertial cavitation) during the ablation period (Chen et al. 2003). Therefore, we believe that the bubbles responsible for attenuating the incident US were not the original UCA microbubbles. The provision of sufficient nuclei provided by UCA allowed repeated inertial cavitation to occur, which thereby induced stronger attenuation than that due to the linear oscillations of UCA bubbles alone. Further studies and simulation are necessary to elucidate the exact role of UCA in HIFU ablation.

According to the temperature measurements listed in Table 5, the following observations held true, irrespective of the electrical power: (1) the temperature was higher at point $\mathrm{A}$ than at point $\mathrm{B}$ in control phantoms, (2) the temperature was higher at point $\mathrm{B}$ than at point $\mathrm{A}$ in phantoms containing UCA, (3) the temperature at point A was higher in control phantoms than in those containing UCA, (4) the temperature at point B was higher in phantoms containing UCA than in control phantoms, and (5) the addition of UCA reduced the temperature difference between points A and B. Therefore, the addition of UCA resulted in the US energy being distributed in a larger volume and resulted in both a larger high-temperature area and an enlarged lesion.

Several issues remain to be investigated before attempting to apply the results of the present study to clinical situations. First, there was no perfusion inside our phantoms and, hence, the UCA microbubbles were evenly distributed and fixed. In contrast, after an intravenous bolus injection or during the administration via a drip in vivo, the contrast microbubbles circulation will be restricted to the circulatory system because UCA cannot penetrate the endothelial barriers: in the presence of a strong US field, mobile bubbles may behave quite differently from those that cannot move.

Second, for diagnostic situations, the administration of a vial of Definity ${ }^{\circledR}(1.5 \mathrm{~mL})$ should result in a maximal bolus concentration of $0.03 \%$ (assuming that the blood volume of a human is $5000 \mathrm{~mL}$ ). Our experimental results suggest that this concentration would make the lesion shift toward the transducer by more than $2 \mathrm{~cm}$. However, the in vivo concentration of UCA changes continuously over time, because bubble destruction oc- 
curs continuously. Therefore, the amount of UCA required to enhance the thermal effect can only be determined experimentally, or by measuring the in vivo concentration of UCA immediately before the ablation and probably also during it. Unfortunately, a reliable method for monitoring the concentration and distribution of UCA in real tissue in vivo is not yet available.

Takegami et al. (2005) compared the effect of using perflutren protein type-A microspheres $\left(\right.$ Optison ${ }^{\circledR}$ ) and MRX-133 to enhance the heating and the coagulation volume in HIFU therapy. They injected approximately $1.5 \times 10^{9}$ microbubbles, equivalent to $5.4 \times 10^{6}$ bubbles $/ \mathrm{mL}$ (assuming $280 \mathrm{~mL}$ of blood in a 4-kg Japan white rabbit), which is close to $0.05 \%$ UCA in our experiments. According to our results, a much lower concentration, such as $0.001 \%$, is sufficient for a substantial degree of heat enhancement. Higher UCA concentration may induce excessive lesion shifting or even surface burning.

Third, the attenuation coefficient of our tissue phantoms was between 2 and $3 \mathrm{~Np} / \mathrm{m} / \mathrm{MHz}$, which is much smaller than that of real tissue. A larger lesion and a different backward shift might occur in real situations. We are working on adjusting the compositions of the tissue phantom to increase the attenuation coefficient to a more biologically realistic level (at least $5 \mathrm{~Np} / \mathrm{m} / \mathrm{MHz}$ ).

The visible holes shown in Fig. 7a were believed to be the action of boiling. The water in phantoms boiled and formed large vapor bubbles, which pushed the mesh networks of polyacrylamide molecules away and created visible cavities. According to our previous experiments, these cavities might disappear after a few days, which was longer than the expected duration of bubble dissolution. Inertial cavitation occurred in phantoms with UCA and produced bubbles. However, these bubbles seemed to be much smaller and, only a few minutes after the sonication, no visible cavities were left (Fig. 7b).

In conclusion, the use of UCA can substantially increase the size of a single lesion and reduce the energy required for HIFU ablation and, thus can shorten the overall treatment time. However, UCA will also induce shifting of the maximal heating position, which might cause unwanted side effects during clinical applications. By compromising between the size enlargement and position shift, the optimal condition was $0.001 \%$ UCA at $50 \mathrm{~W}$, which produced lesions that were 12 times larger than that in the control phantoms without UCA, but with an acceptable shift of $0.65 \mathrm{~cm}$. Further studies, especially in vivo investigations, are mandatory for applying UCAenhanced thermal ablations in clinical situations.

Acknowledgements-This research was supported by grants from the National Science Council (no. 93 to 2320-B-002 to 097-) and the National Taiwan University Hospital (no. 94A14).

\section{REFERENCES}

Carstensen EL, Kelly P, Church CC, et al. Lysis of erythrocytes by exposure to CW ultrasound. Ultrasound Med Biol 1993;19:147165.

Chen WS, Lafon C, Matula TJ, Vaezy S, Crum LA. Mechanisms of lesion formation in high intensity focused ultrasound therapy. Acoust Res Lett Online 2003;4:41-46.

Deng CX, Xu Q, Apfel RE, Holland CK. Inertial cavitation produced by pulsed ultrasound in controlled host media. J Acoust Soc Am 1996;100:1199-1208.

Fujishiro S, Mitsumori M, Nishimura Y, et al. Increased heating efficiency of hyperthermia using an ultrasound contrast agent: A phantom study. Int J Hypertherm 1998;14:495-502.

Kaneko Y, Maruyama T, Takegami K, et al. Use of a microbubble agent to increase the effects of high intensity focused ultrasound on liver tissue. Eur Radiol 2005;15:1415-1420.

McDannold N, Moss M, Killiany R, et al. MRI-guided focused ultrasound surgery in the brain: Tests in a primate model. Magnet Reson Med 2003;49:1188-1191.

Takegami K, Kaneko Y, Watanabe T, et al. Polyacrylamide gel containing egg white as new model for irradiation experiments using focused ultrasound. Ultrasound Med Biol 2004;30:1419-1422.

Takegami K, Kaneko Y, Watanabe T, et al. Heating and coagulation volume obtained with high-intensity focused ultrasound therapy: Comparison of perflutren protein-type A microspheres and MRX133 in rabbits. Radiology 2005;237:132-136.

Tempany CM, Stewart EA, McDannold N, et al. MR imaging-guided focused ultrasound surgery of uterine leiomyomas: A feasibility study. Radiology 2003;226:897-905.

Tran BC, Seo J, Hall TL, Fowlkes JB, Cain CA. Microbubble-enhanced cavitation for noninvasive ultrasound surgery. IEEE Trans Ultrason Ferroelectr Freq Control 2003;50:1296-1304.

Watkin NA, ter Haar GR, Rivens I. The intensity dependence of the site of maximal energy deposition in focused ultrasound surgery. U1trasound Med Biol 1996;22:483-491.

Yu T, Wang G, Hu K, et al. A microbubble agent improves the therapeutic efficiency of high intensity focused ultrasound: A rabbit kidney study. Urol Res 2004;32:14-19. 